\title{
PENGARUH MODEL PEMBELAJARAN KOOPERATIF TIPE STAD DAN GAYA BELAJAR SISWA TERHADAP HASIL BELAJAR MATEMATIKA SISWA KELAS VII SMP NEGERI 19 KERINCI
}

\author{
Sabri Amin ${ }^{1}$, Kamid $^{2}$, Muhaimin ${ }^{3}$ \\ Program Studi Magister Pendidikan Matematika, Universitas Jambi ${ }^{1,2,3}$ \\ E-mail: sabriamin429@gmail.com
}

\begin{abstract}
ABSTRAK
Penelitian ini dilatarbelakangi oleh adanya upaya yang dapat dilakukan guru untuk membantu siswa agar aktif dalam prose pembelajaran dengan menggunkan model pembelajaran yang tepat guna dan sesuai dengan tujuan pembelajaran. Adapun tujuan dari penelitian yang dilakukan ini adalah untuk mengetahui pengaruh model pembelajaran kooperatif tipe STAD dan gaya belajar terhadap hasil belajara siswa. Penelitian ini menggunakan qusi eksperimen dengan rancangan non equivalen pre-test and pos tes control group desigt. Pengumpulan data dilakukan dengan menggunakan instrumen tes soal untuk melihat hasil belajar matematika siswa dan angket gaya belajar untuk melihat gaya belajar siswa. Analisis data dilakukan dengan menggunakan uji non parametrik dengan Kruskal-wallis pada taraf signifikan 5\%. Hasil penelitian menunjukkan terdapat pengaruh antara pembelajaran yang menggunakan model kooperatif tipe stad dengan pendekatan konvensional halini dapat dilihat dari hasil uji hipotesis kruskal-walis adalah nilai Asyim.sig $<0,05$ maka dapat diketahui $0,018<0,05$ terdapat pengaruh yang signifikan antara model pembelajaran kooperatif tipe stad terhadap hasil belajar matematika siswa SMP Negeri 19 Kerinci. Tidak terdapat pengaruh gaya belajar siswa terhadap hasil belajar matematika siswa SMP Negeri 19 Kerinci hasil uji dapat dilihat dari nilai Asym.sig > 0,05 maka dapat diketahui 0,980 > 0,05 tidak terdapat pengaruh gaya belajar siswa terhadap hasil belajar siswa. Tidak terdapat interksi antara model pembelajaran koperatif tipe STAD dan gaya belajar siswa SMP Negeri 19 Kerinci. Rata-rata hasil belajaran pada kelas yang menggunakan model STAD 68,29, kelas yang menggunakan model STAD dengan media 69,34, dan sedangkan kelas yang menggunakan pedekatan konvensional 61,04.
\end{abstract}

Kata kunci:

Gaya Belajar; Model Pembelajaran STAD.

\begin{abstract}
This research is motivated by the efforts that can be made by the teacher to help students to be active in the learning process by using appropriate learning models and in accordance with the learning objectives. The purpose of this research is to determine the effect of STAD type cooperative learning models and learning styles on student learning outcomes. This study used an experimental qusi with a non equivalent design pre-test and post test control group design. Data collection is done by using the test instrument to see the results of student mathematics learning and learning style questionnaires to see student learning styles. Data analysis was performed using a non-parametric test with Kruskal-wallis at a significant level of 5\%. The results showed that there was an influence between learning using the cooperative type stad model and conventional approaches. It can be seen from the results of the kruskal-walis hypothesis test that the value of Asyim. cooperative type of learning towards mathematics learning outcomes of 19 Kerinci Junior High School students. There is no influence of student learning styles on mathematics learning outcomes of students of SMP Negeri 19 Kerinci test results can be seen from the value of Asym.sig > 0.05, it can be seen 0.980>0.05 there is no influence of student learning styles on student learning outcomes. There is no interaction between the STAD type cooperative learning model and the learning styles of 19 Kerinci Junior High School students. The average learning outcomes in the class using the STAD model 68.29, the class using the STAD model with 69.34 media, and while the class using the conventional approach 61.04.
\end{abstract}

Keywords:

Learning Style; STAD Learning Model. 


\section{$\pi$ (Phi)}

\section{PENDAHULUAN}

Sebagai salah satu mata pelajaran yang selalu dipelajari siswa dari mulai tingkat sekolah dasar sampai sekolah menengah atas bahkan juga sampai pada perguruan tinggi, terdapat banyak alasan mengapa sangat pentingnya siswa mempelajari mata pelajaran matematika antara lain sebagai sarana berpikir yang logis, sebagai pengetahuan untuk menyelesaikan masalah didalam sehari-hari, sarana pengembangan kreatifitas.

Pada proses belajar mengajar peran guru sebagai salah satu instrumen yang sangat penting untuk meningkatkan prestasi dari siswa. Namun, guru hanya sebagai fasilitator dimana sebenarnya siswa memiliki kesempatan dalam menentukan pencapaian kompetensi yang perlu diraihnya. Namun, pada kenyataannya dalam pembelajaran sering kali guru kurang melibatkan siswa secara aktif, sehingga siswa kurang terlatih untuk mengembangkan kemampuan dirinya.

Salah satu faktor yang dapat mempengaruhi dari hasil belajar siswa adalah faktor internal yang mana berasal dari dalam diri siswa tersebut salah satu faktor internal yang dimaksud adalah gaya belajar yang terdapat pada siswa tersebut, siswa memiliki gaya belajar yang berbeda disinilah dibutuhkan kemampuan seorang guru untuk melihat gaya belajar apa yang paling baik yang bisa diterapkan pada siswa tersebut.

Untuk meningkatkan hasil belajar siswa diperlukannya suatu model yang tepat dalam proses pembelajaran dan guru harus mempunyai kreatifitas yang tinggi didalam mengolah kelasnya sehingga dapat menjadi kelas yang menyenangkan dan disukai oleh siswanya sehingga nantinya akan berdampak langsung dengan hasil belajar yang akan diperoleh oleh siswa. oleh karena itu model pembelajaran kooperatif merupakan model yang bisa digunakan oleh guru untuk meningkatkan hasil belajar siswa.

Ngalimun (2013: 161) Model pembelajaran kooperatif adalah kegiatan pembelajaran secara berkelompok untuk bekerja sama saling membantu dalam menyelesaikan persoalan. Hal yang harus diperhatikan didalam pembelajaran kooperatif bagaimana kita mengatur strategi pembelajaran, membentuk kelompok yang heterogen didalam kelas, kerja sama dalam kelompok, presentasi hasil kelompok, dan pelaporan. Inti dari sebuah proses pembelajaran kooperatif bagaimana guru bisa mengkoordinir kelompok-kelompok kecil didalam kelas untuk mencapai tujuan pembelajaran.

Menurut Slavin (2005: 143), model pembelajaran STAD merupakan model pembelajaran kolaboratif yang sangat sederhana dan merupakan model yang dapat digunakan sebagai titik awal bagi guru yang ingin menggunakan model pembelajaran kolaboratif.

Menurut Deporter \& Hernacki (2005) gaya belajar adalah proses seseorang untuk menyerap, dan mengolah berbagai informasi yang didapatkan, semakin tepat gaya belajar yang diterapkan dalam proses pembelajaran maka semakin besar kesuksesan belajar yang dimiliki.

Gaya belajar yang diperoleh setiap siswa dapat meningkatkan Hasil belajar yang dapat diperoleh siswa. pada hakikatnya kompilasi guru menerapkan gaya belajar yang tepat maka akan berdampak langsung terhadap hasil belajar siswa yang lebih baik, namun demikian pula sebaliknya jika gaya belajar yang diterapkan oleh seorang guru tidak tepat makan hasil belajar yang didapatkan juga akan tidak memuaskan.

Berdasarkan latar belakang tersebut, maka salah satu upaya yang dapat dilakukan guru untuk membantu siswa agar aktif dalam prose pembelajaran adalah model pembelajaran yang tepat guna dan tujuan pembelajaran yang dapat dilakukan. Salah satu model pembelajaran yang memungkinkan siswa mengembangkan pengetahuan, kemampuan dan keterampilan yang sesuai dengan kebutuhan, dan demokrasi adalah model pembelajaran kooperatif Student Team Achievement Divisions (STAD). Karena itu dilakukan 


\section{$\pi$ (Phi)}

penelitian dengan judul pengaruh model pembelajaran kooperatif tipe stad dan gaya belajar siswa terhadap hasil belajar matematika siswa kelas VII SMP Negeri 19 Kerinci. Adapun tujuan dari penelitian ini untuk mengetahui pengaruh model pembelajaran kooperatif tipe STAD dan gaya belajar terhadap hasil belajara siswa.

\section{METODE PENELITIAN}

Berdasarkan tujuan penelitian, penelitian ini merupakan penelitian quasi eksperimen (arikunto 006:3). Dalam penerapannya, penelitian ini menggunakan dua siswa kelompok yaitu kelompok eksperimen dan kelompok kontrol. Pada kelompok eksperimen pertama dengan menggunkan model pembelajaran kooperatif tipe STAD, dan untuk kelas eksperimen kedua dengan menggunakan model kooperatid tipe SDAT dan Media, sedangkan pada kelompok control dengan menggunakan model pembelajaran konvensional.

Terdapat tiga variabel yang digunakan dalam penelitian ini yang mana untuk variabel bebas dengan menggunkan model kooperatif tipe STAD,dan untuk variabel terikat yaitu hasil belajar siswa sedangkan gaya belajar merupakan variabel moderat.

Pada penelitian ini dilaksanakan pada semester ganjil tahun pelajaran 2019/2020 yang bertempat di SMP Negeri 19 Kerinci. Berlangsung pada tanggal 07 Oktober - 07 November. Untuk teknik pengambilan sampel yang digunakan adalah Nonprobability Sampling. Teknik Nonprobability Sampling digunakan adalah sampel jenuh (Total Sampling) yang merupakan apabila semua anggota populasi dipilih sebagai sampel(Suryabrata,2014).

Terdapat beberapa tahapan prosedur didalam penelitian ini. Setelah menentukan sampel maka setiap kelas diberikan pre test untuk mengetahui kemampuan awal siswa. Selanjutnya diberikan akan diberikan perlakukan pada kelas eksperimen dengan menggunakan perlakuan model koopertif tipe STAD pada kelas eksperimen dan model konvensional pada kelas control. Selanjutnya memberikan angket gaya belajar kepada setiap siswa sesuai dengan keadaan yang dialami dan rasakan pada masingmasing siswa kemudian dilakukan Pos-Test untuk melihat hasil belajar matematika siswa.

Adapun instrument yang digunakan pada penelitian ini adalah instrument test dan kuisioner. Tes dengan menggunakan berupa tes tertulis dengan memberikan soal uraian sebanyak 10 soal yang telah divalidasi. Selanjutnya instrument ini diberikan kepada subjek penelitian. Selanjutnya ketika data sudah diperoleh dari subjek penelitian maka dilakukan analisis sesuai dengan tujuan penelitian. Sebelum instrument digunakan sebagai alat untuk mengumpulkan data, instrument tersebut terlebih dahulu diuji cobakan pada siswa yang bukan sampel dengan tujuan untuk mendapatkan soal yang baik, maka dilakukan uji statistik berupa validitas, reabilitas tes, daya beda dan indek kesukaran soal. Instrument penelitian selanjutnya adalah skala gaya belajar siswa.

Selanjutnya unruk mendapatkan hasil dalam penelitian ini, maka diperlukan analisis data terhadap data yang didapatkan. Agar mendapatkan bukti apakah terdapat pengaruh model pembelajaran kooperatif tipe STAD dan gaya belajar siswa terhadap hasil belajar matematika siswa. Sebelum melakukan analisis data, maka terlebih dahulu melakukan uji normalitas terhadap populasi dan uji homogenitas terhadap variable penelitian.

Berdaarkan hipotesis penelitian, maka untuk menguji hipotesiss tersebut digunakan kruskal wallis, karena data yang didapatkan berdistribusi tidak normal maka dilakukan uji kruskal wallis dan tidak dapat dilanjutkan dengan uji tukey. 


\section{HASIL DAN PEMBAHASAN}

1. Hasil Belajara Matematika Siswa Kelas Eksperimen 1, Eksperimen 2, dan Kelas Kontrol

Hasil belajar matematika siswa diperoleh setelah dilakukan tes akhir pada kelas eksperimen 1, kelas eksperimen 2, dan kelas control. Hasil penelitian ini menunjukkan hasil tertinggi dan terendah untuk kelas eksperien 1 yang mana kelas eksperimen 1 dengan model kooperatif tipe STAD adalah 90 dan 40, pada kelas eksperimen 2 yaitu kelas dengan menggunakan model kooperatif tipe STAD dengan menggunakan media pembelajaran adalah 90 dan 40, selanjutnya pada kelas control ddengan menggunakan pendekatan konvensional adalaah 70 dan 30, untuk nilai rata-rata untuk kelas dengan model kooperatif tipe STAD adalah 68,26, kelas model kooperatif dengan menggunakan media adalah 69,34, dan pada kelas control dengan pedekatan konvensional 61,04. Median kelas dengan menggunakan model kooperatif tipe STAD adalah 75,00, median model kooperatif tioe STD dengan media 75,00 , sedangkan median pendekatan konvensional adalah 65,00. Modus kelas menggunakan model kooperatif tipe STAD adalah 80, model kooperatif tipe STAD dan media 80, dan dengan pendekatan konvensional adalah 65, Varians untuk kelas eksperimen 1 dengan model kooperatif tipe STAD adalah 222, 962, kelas eksperimen 2 model kooperatif tipe STAD dan media adalah 237,846, sedangkan kelas control dengan pendekatan konvensional adalah 257, 201.

\section{Hasil Belajar Matematika Siswa yang Menggunakan Model Kooperatif Tipe STAD}

Hasil penelitian menunjukkan hasil belajar siswa kelas eksperimen 1 yang menggunakan model kooperatif tipe STAD dan gaya belajar siswa diperoleh rata-rata nilai siswa yang mana dilakukan sebelum dilakukan perlakuan model kooperatif tipe
STAD adalah 55,38 dan setelah dilakukan perlakuan dengan model koperatif tipe STAD dengan materi bentuk aljabar dengan nilai rata-rata yang diperoleh adalah 68,26. Dapat disimpulkan bahwa terjadi peningkatan yang signifikan perolehan nilai rata-rata matematika yang menggunakan model kooperatif tipe STAD dan gaya belajar siswa.

\section{Hasil Belajar Matematika Siswa yang Menggunakan Model Kooperatif Tipe STAD dengan Menggunakan Media dan Gaya Belajar}

Hasil belajar siswa dikelas eksperimen dengan menerapkan model kooperatif tipe STAD dengan menggunakan media pembelajaran dan gaya belajar siswa diperoleh nilai rata-rata tes awal yang mana tes dilakukan sebelum dilakukan perlakuan model kooperatif tipe STAD dengan menggunakan media pembelajaran adalah 54,78 dan tes akhir dilakukan dilakukan setelah dilakukan perlakuan dengan model kooperatif tipe STAD dengan menggunakan media pembelajaran pada materi bentuk aljabar diperoleh nilai rata-rata sebesar 69,34. Dapat disimpulkan terdapat pengaruh yang signifikan perolehan nilai rata-rata siswa yang menggunakan model kooperatif tipe STAD dengan menggunakan media dan gaya belajar siswa.

\section{Hasil Belajar Matematika Siswa yang Menggunakan Pendekatan \\ Konvensional dan Gaya Belajar.}

Hasil belajar matematika siswa dikelas konrol dengan menerapkan pendekatan konvensional dan gaya belajar siswa diperoleh nilai rata-rata tes awal yang mana tes dilakukan sebelum dilakukan perlakuan pendekatan konvensional adalah 55,20 dan tes akhir dilakukan dilakukan setelah dilakukan perlakuan dengan pendekatan konvensional pada materi bentuk aljabar diperoleh nilai rata-rata sebesar 69,34. Dapat disimpulkan terdapat peningkatan perolehan nilai rata-rata siswa yang menggunakan 


\section{$\pi$ (Phi)}

pendekatan konvensional dan gaya belajar siswa.

Untuk melihat pengaruh dari setiap variabel penelitian selanjutnya dilakukan uji hipotesis dengan menggunakan uji analisis kruskal wallis adapun hasil pengujian tersaji pada tabel 1. Brdasarkan tabel 1 dijelaskan hasil uji hipotesis dan keputusan dari hasil analisis tersebut yaitu sebagai berikut:

Hipotesis 1

Susuai dengan rumusan masalah dalam penelitian ini apakah terdapat pengaruh model pembelajaran kooperatif tipe STAD terhadaphasil belajar matematika siswa dan gaya belajar siswa terlihat dari hasil analisis adalah 0,018 nilai probabilitas tersebut lebih kecil dari pada 0,05 $(<0,05)$ maka $\mathrm{H}_{0}$ ditolak. Dengan kata lain terdapat pengaruh model kooperatif tipe STAD terhadap hasil hasil belajara matematika siswa. Kelas VII SMP.

Hipotesis 2

Berdasarkan

Berdasarkan rumusan masalah apakah terdapat pengaruh gaya belajar terhadap hasil belajar siswa matematika siswa, dapat dilihat bahwa untuk variabel gaya belajar sebesar 0,980, dari hasil 0,980 nilai probabilitas tersebut lebih besar dari 0,05(>0,05) maka $\mathrm{H}_{0}$ diterima dan $\mathrm{H}_{1}$ ditolak dengan kata lain tidak terdapat pengaruh gaya belajar siswa terhadap hasil belajar matematika siswa kelas VII SMP.

Hipotesis 3

Berdasarkan rumusan masalah selanjutnya apakah terdapat interaksi antara model koopertaif tipe STAD dan gaya belajar siswa, dikarenakan salah satu dari variabel berdistribusi tidak normal maka untuk hipotesis ke 3 tidak dapat kita ujikan karena tidak memenuhi syarat uji interaksi.

\section{SIMPULAN DAN SARAN}

Berdasarkan hasil penelitian yang di laksanakan, dapat disimpulkan bahwa (1) terdapat pengaruh model kooperatif tipe STAD terhadap hasil belajar matematika siswa kelas VII, (2) tidak terdapat pengaruh gaya belajar terhadap hasil belajar atematika siswa kelas VII SMP dan (3) tidak terdapat interaksi antara model kooperatif tipe STAD dan gaya belajar siswa kelas VII SMP.

Adapun saran dari hasil penelitian ini, agar guru dapat menjadikan model pembelajaran kooperatif tipe STAD sebagai salah satu model pembelajaran bagi siswa.

\section{DAFTAR PUSTAKA}

Nurdiyan, A. I. (2017). Pengaruh Model Kooperatif Tipe STAD Terhadap Sikap Tanggung Jawab. Jurnal Ilmiah FKIP Universita Subang, (2)2, 2017.

Creswell, J. W. (2010). Research Design Pendekatan Kualitatif, Kuantitatif, dan Mixed. Yogyakarta: Pustaka Belajar.

Dara S, Virga. (2015). Pengaruh Model Pembelajarankooperatif Tipe Stad Terhadap Aktivitas Belajar Mahasiswa Pada Mata Kuliah Manajemen Keuangan Lanjutan Di Prodi Akutansi. Jurnal Universitas Pendidikan Indonesia, 2017.

Djamuri, dkk. (2015). Pengaruh Model Pembelajaran STAD Berbasis Multimedia Interaktif Terhadap Penguasaan Konsep Siswa Pada Materi Termodinamika. Jurnal Penelitian Pendidikan IPA ( JPPIPA). (1)1, 2015.

I Putu Ari Sudana, I. P., Wesana, I.G. (2017). Penerapan Model Pembelajaran Kooperatif Tipe STAD Untuk Meningkatkan Hasil Belajar IPA. Jurnal Ilmiah Sekolah Dasar, (1)1, 2018.

Khoeron. I. R, Sumarna, N., Permana, T. (2014). Pengaruh Gaya Belajar Terhadap Prestasi Belajar Peserta Didik Pada Mata Pelajaran Produktif. Journal oF Mechanical Engineering Education, (1)2, 2014.

Lestari, K.E. \& Yudhanegara, M.R. (2015). Penelitian Pendidikan Matematika. Bandung: Refika Aditama.

Bire, A. L., Geradus, U., Bire, J. (2014) Pengaruh Gaya Belajar Visual 
Auditorial, Dan Kinestetik Terhadap Prestasi Belajar Siswa. Jurnal Pendidikan, (44)2, 2014.

Majid, A. (2013). Strategi Pembelajaran. Bandung: Remaja Rosdakarya.

Nasution. (2013). Berbagai Pendekatan Dalam Proses Bekajar \& Mengajar. Jakarta: Bumi Aksara.

Rusman. (2013). Model-model Pembelajaran Profesionalisme Guru Jakarta: Rajawali Pers.

Slameto. (2010). Belajar dan Faktor-Faktor Yang Mempengaruhinya. Jakarta: Rineka Cipta.

Tim Penyusun. (2015). Pedoman Penulisan Tesis. Jambi: Program Megister Pendidikan Matematika Fakultas Keguruan dan Ilmu Pendidikan Universitas Jambi. 